\title{
Extraction of Topographic Features using DSM and Ortho Image for Disaster Prevention
}

\author{
Joon-Kyu Park ${ }^{1}$ and Keun-Wang Lee ${ }^{2 *}$ \\ ${ }^{1}$ Dept. of Civil Engineering, Seoil University, \\ 28, Yongmasan-ro 90-gil, Jungnang-gu, Seoul, Korea \\ ${ }^{2}$ Dept. of the Multimedia Science, Chungwoon University, \\ 113, Sukgol-ro, Nam-Gu, Incheon, Korea \\ surveyp@empas.com,kwlee@chungwoon.ac.kr
}

\begin{abstract}
In recent years, natural and man-made disasters have been increasing due to changes in the environment and ecosystem due to extreme weather events and global warming in South Korean. It is time for scientific analysis and systematic disaster management to protect people and property from recurrent disasters. In this study, UAV(Unmanned Aerial Vehicle) was used for construction of geospatial information about study area. And UAV data such as ortho image and DSM(Digital Surface Model) were classified using eCognition into water, beach and buildings in order to application for disaster prevention information. As a result, UAV data were classified by object-based classification methods effectively. The disaster information by UAV data and classification method is expected to be available for basic data of the disaster prevention field.
\end{abstract}

Keywords: Geospatial Information, UAV, Ortho Image, Digital Surface Model, Extraction, Topographic Feature, Disaster Prevention

\section{Introduction}

Recently, large-scale natural disasters such as typhoons, floods and snowy seasons have been occurring all over Southeast Asia, North America, and South America due to global warming and weather changes[1][2]. In Korea, the risks of earthquakes and tsunamis, which have been regarded as safe havens, are also increasing. Disaster types such as typhoons, floods, heat waves, and heavy snowfalls are also diversifying and the scale of damage is also on the rise[3][4]. In addition, due to geographical characteristics or lack of infrastructure, disasters tended to occur intensively around a specific region or city in the past but disasters occur throughout the country in recent years so preparation for disaster prevention has emerged as an urgent challenge issue[5][6]. In the past, the extent of the disaster occurred concentrated on a specific area or city. However disasters have occurred throughout the country and measures are needed to prevent disasters [7][8]. In this study, UAV was used for construction of ortho image and DSM(Digital Surface Model) about study area. And topographical features were extracted using ortho image and DSM by eCognition software for construction of disaster prevention. Figure 1 shows study flow.

${ }^{*}$ Corresponding author. 




Figure 1. Study Flow

\section{UAV Data Acquisition and Processing}

The study area of this research is Daecheon beach, Boryung-si, Chungcheongnam-do. The area was exterminated but the monitoring for new infection trees was necessary. That was why the area was the object. The Figure 2 is the study area.

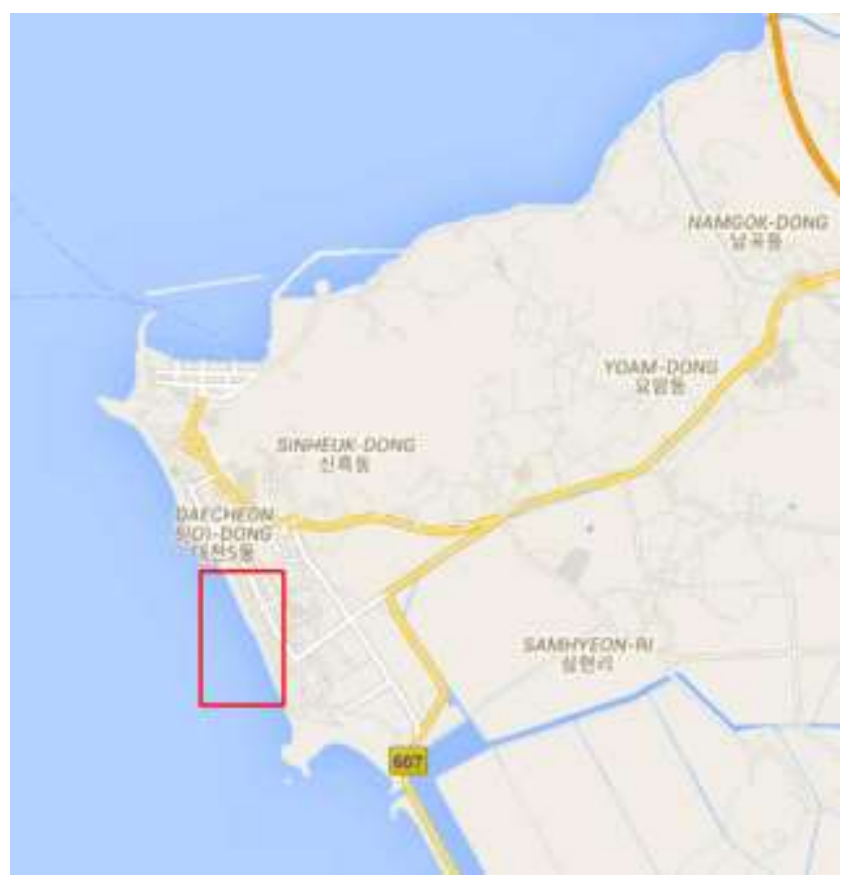

Figure 2. Study Area 
The Cases of image obtaining by using UAV increased to research various kinds of UAV actively. In this study, UX5 with RGB sensor was used to obtain images. Figure 3 shows UAV[10].

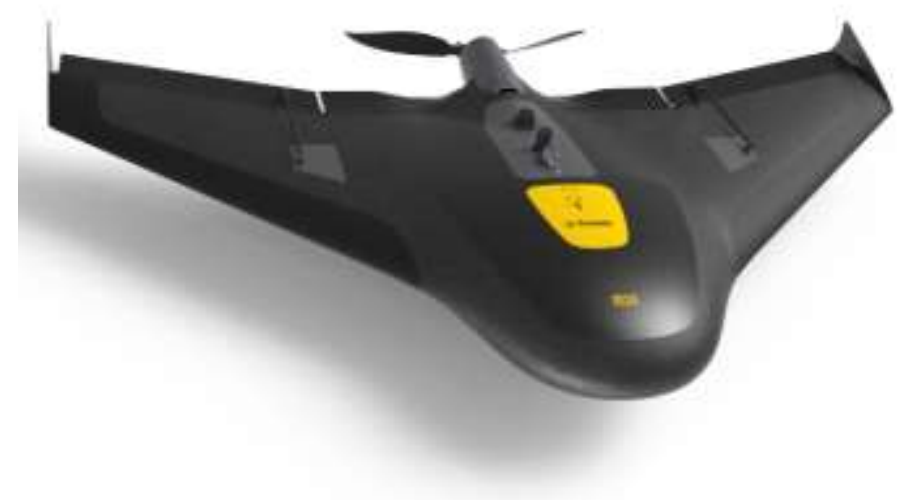

Figure 3. UAV

UX5 could be equipped with GPS, digital camera, radio antenna, Pitot tube and other sensors. GPS receiver measured time difference of signals from each satellite to convert into distance and to estimate location of the receiver[9]. Sony NEX-5R digital camera was used to take picture with high resolution on ground. The camera with larger sensor than other companies' product having same size had could take high quality picture. Sony NEX-5R was equipped with APS(Advanced Photo System)-C type of sensor same as DSLR, and APS-C type of Exmor APS HD CMOS could take photograph with high sensitivity and low noise. The radio antenna could transmit airplane speed, altitude, coordinates and other flight data to radio modem of the ground controller by wireless communication, and pitot tube measured difference of the pressure between opening of front and that of side to monitor speed and altitude of the airplane and to be placed at eBox. The study area was about $2.1 \mathrm{~km}^{2}$ and flight height of UAV was about $150 \mathrm{~m}$, flight time was about 1 hour. Table 1 shows specification of UAV[10].

Table 1. Specification of UAV

\begin{tabular}{|c|c|}
\hline Item & Description \\
\hline Type & Fixed wing \\
\hline Weight & $2.7 \mathrm{~kg}$ \\
\hline Wingspan & $1 \mathrm{~m}$ \\
\hline Height above take-off location & $75 \mathrm{~m} \sim 750 \mathrm{~m}$ \\
\hline Endurance & $50 \mathrm{~min}$ \\
\hline Cruise speed & $80 \mathrm{~km} / \mathrm{h}$ \\
\hline Camera & Nex-5R $(16.1 \mathrm{MP})$ \\
\hline Resolution & $2.4 \sim 24 \mathrm{~cm}$ \\
\hline
\end{tabular}

The post processing of the UAV dta was done by TBC(Trimble Business Center). The number of the aerial images were 1,252. The degree of overlap of the aerial image is $80 \%$ and ortho image is GSD(Ground Sample Distance) $5 \mathrm{~cm}$. UAV images are imported to data processing module of along with their locations, orientations, and camera calibrations. 
Geometric errors in the raw images from an UAV are significant as a result of the dynamic platform from which they are captured and the imprecision in the UAV's position and orientation sensors[11][12]. To correct for errors in the positions and orientations of the aerial images, we used photogrammetric methods to adjust the photo stations. This is done in data processing module first as an adjustment with tie points. This module automatically finds tie points in all available stations based on state of the art computer vision algorithms, and then the TBC adjusts the stations simultaneously for a best fit. Automatically matched photo tie points are distributed densely over the complete project, even in challenging low-texture terrain. The Figure 4 shows the screen of data processing.

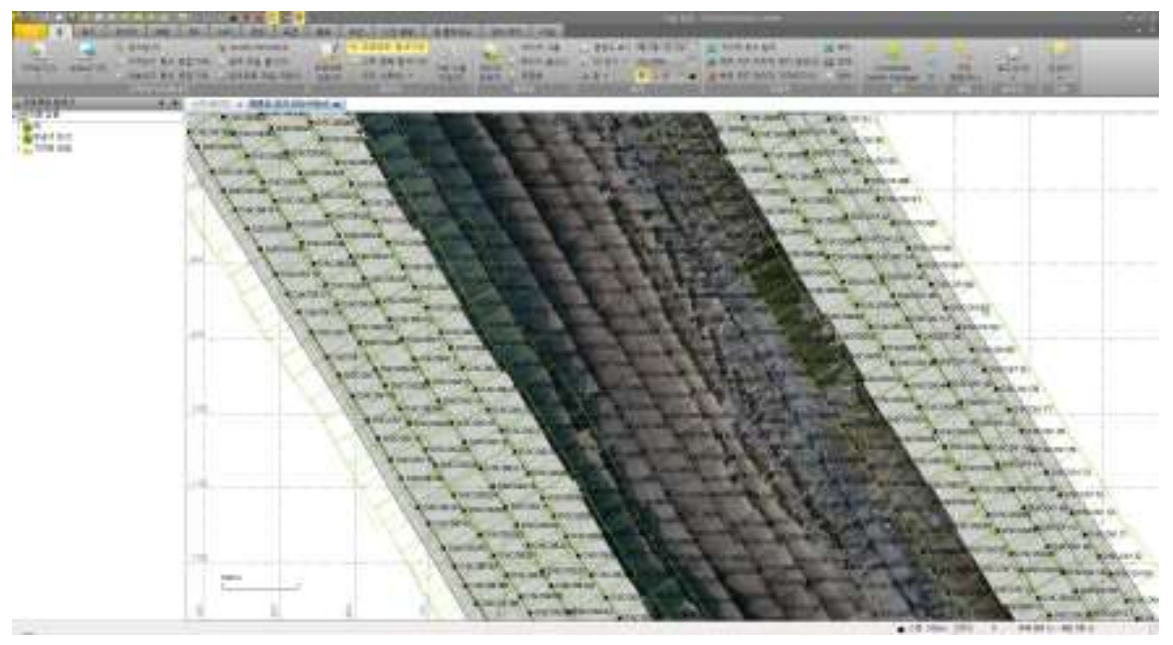

Figure 4. Data Processing Screen

UAV data processing was conducted in the order of tie point extraction, DSM generation and ortho image generation. Figure 5 and Figure 6 show the ortho image and DSM.

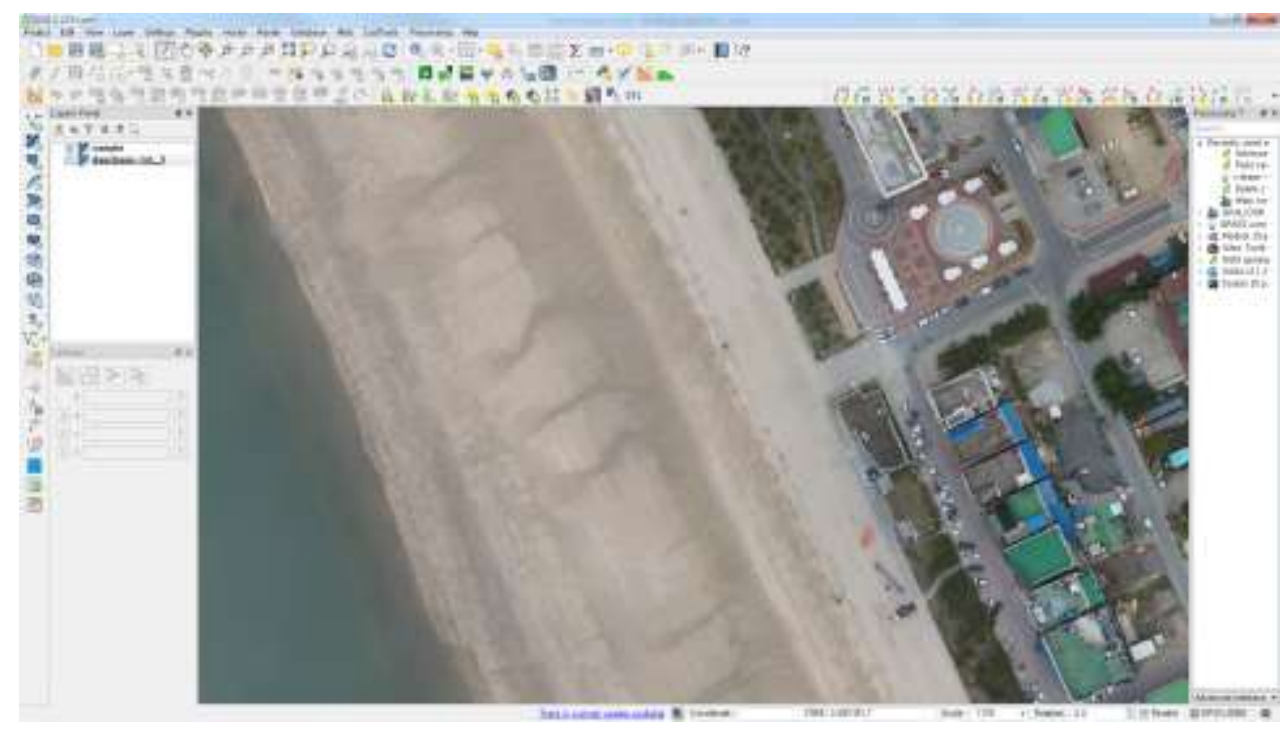

Figure 5. Ortho Image 


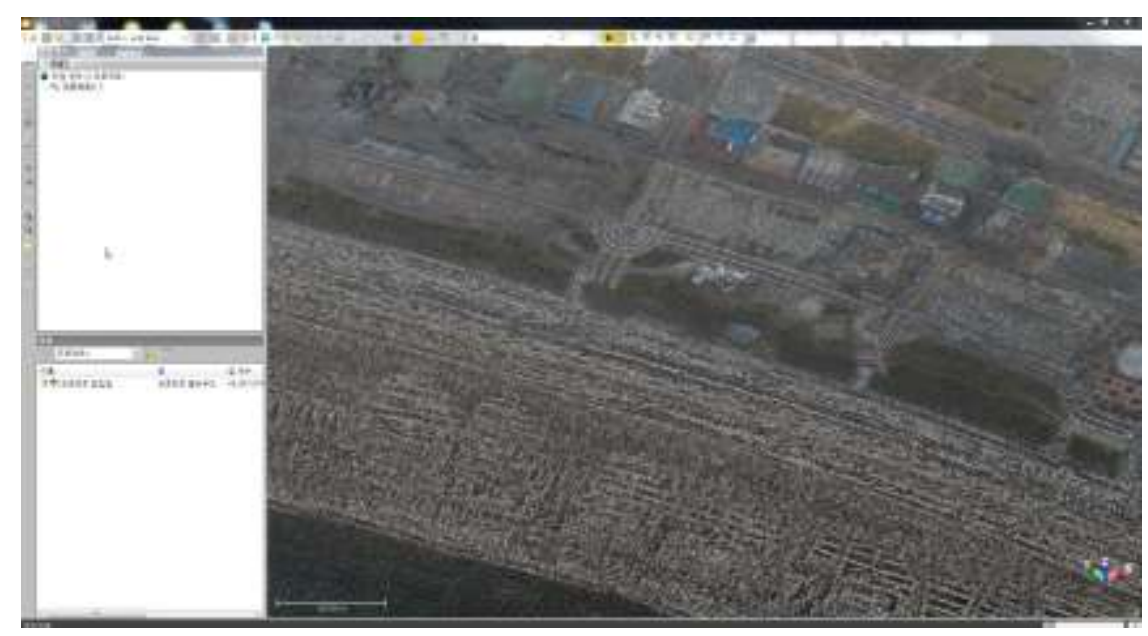

Figure 6. DSM

Basically, ortho image contain a lot of information about terrain and features. Detailed analysis of the disaster area will be possible using ortho images before and after the disaster because resolution of ortho image is very high. In addition, DSM has elevation values of the terrain. If there are time-series DSM data for a particular area, topographic changes such as sedimentation, erosion and landslide can be analyzed.

\section{Extraction of Topographic Features}

In this study, UAV ortho image and DSM were used for feature extraction. eCognition software was used for the extraction. eCognition is the object-based image analysis software. It is used in earth sciences to develop rule sets for the automatic analysis of remote sensing data[12]. Rule set was created for classification of image. The image classification process was performed in the order of segmentation, sea and sand extraction using brightness values. Figure 7 shows steps of topographic feature extraction.

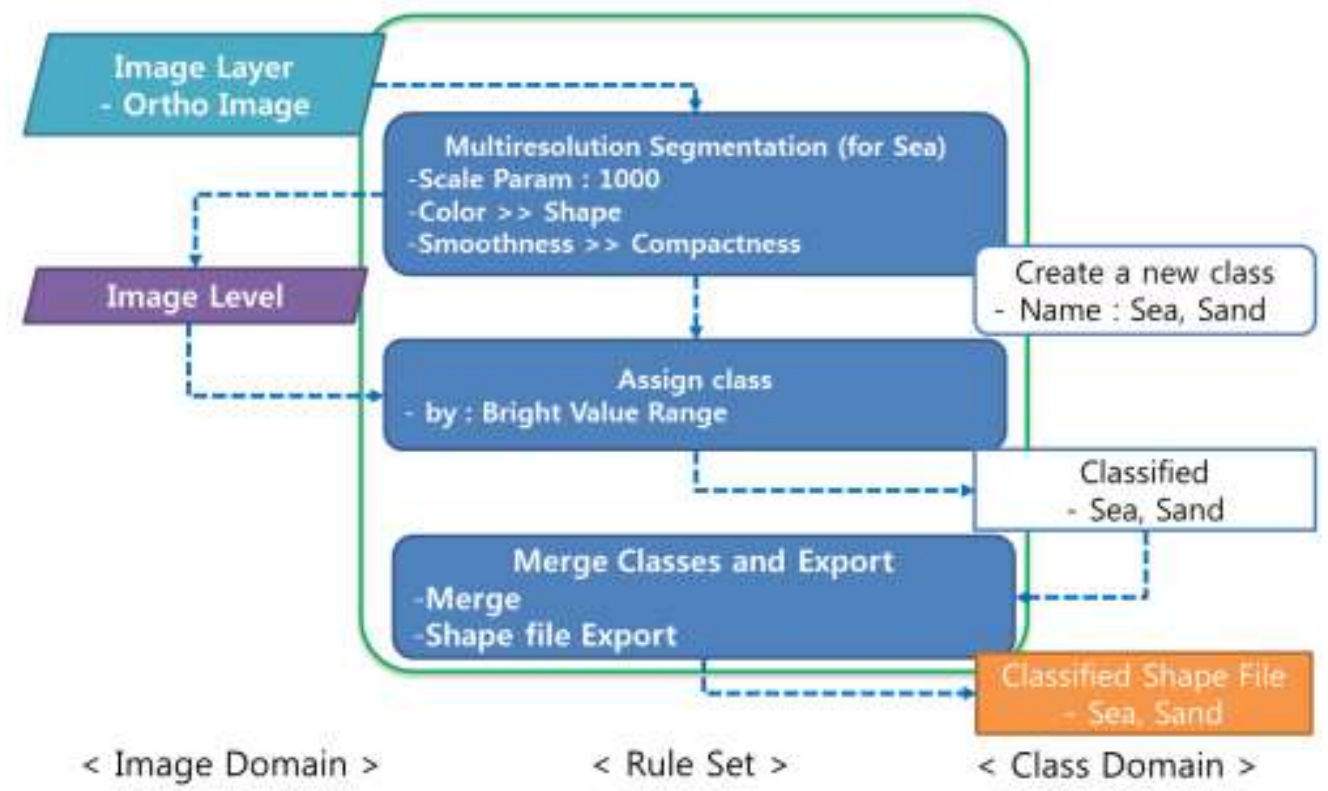

Figure 7. Steps of Topographic Feature Extraction

Purpose of these steps was extraction of sea, sand and others. First of all, the segmentation was performed for extraction. Figure 8 Figure 10 show results of each steps. 


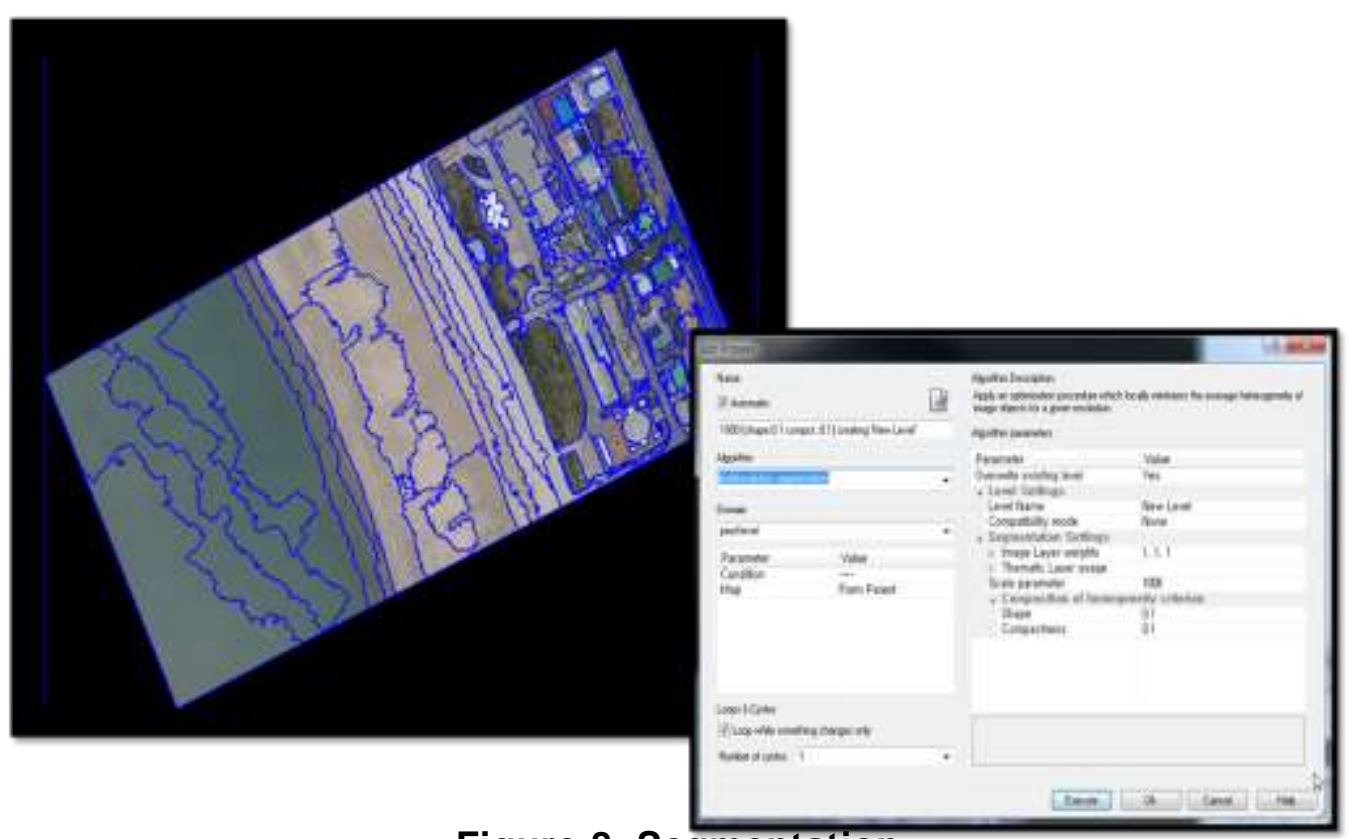

Figure 8. Segmentation

After segmentation, object brightness value check was performed for supervised classification. Figure9 shows brightness value check.

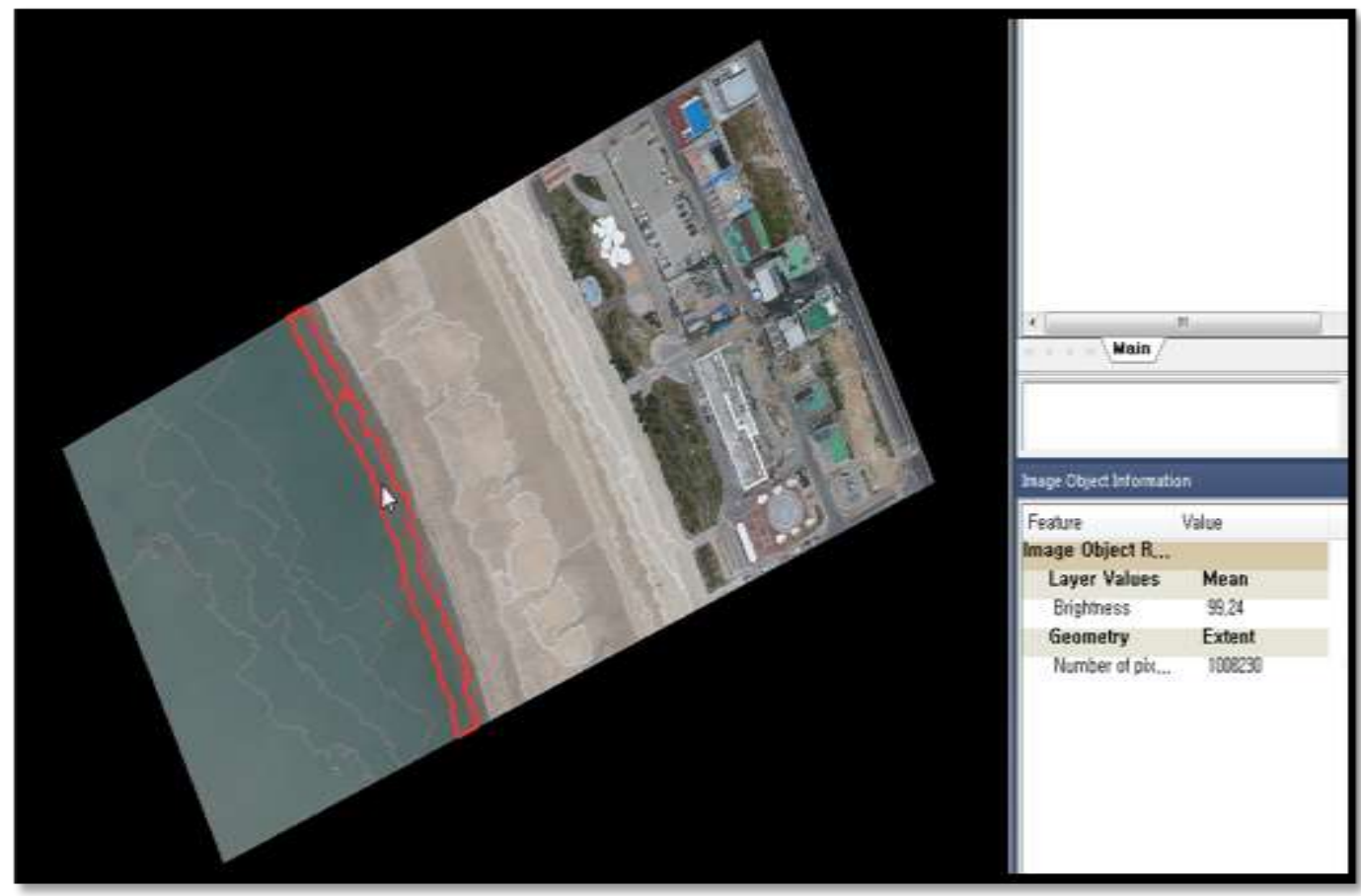

Figure 9. Brightness Value Check

The sea showed brightness values of $95 \sim 109$, and the sand showed brightness values of $149 \sim 185$. So, the thresholds of sea and sand were divided by checking the brightness values. Table 2 shows brightness values of sea and sand and Figure 10 shows feature definition. 
Table 2. Brightness Values of Sea and Sand

\begin{tabular}{|c|c|}
\hline Feature & Value \\
\hline Sea & $94<$ Value $<110$ \\
\hline Sand & $150<$ Value $<186$ \\
\hline
\end{tabular}
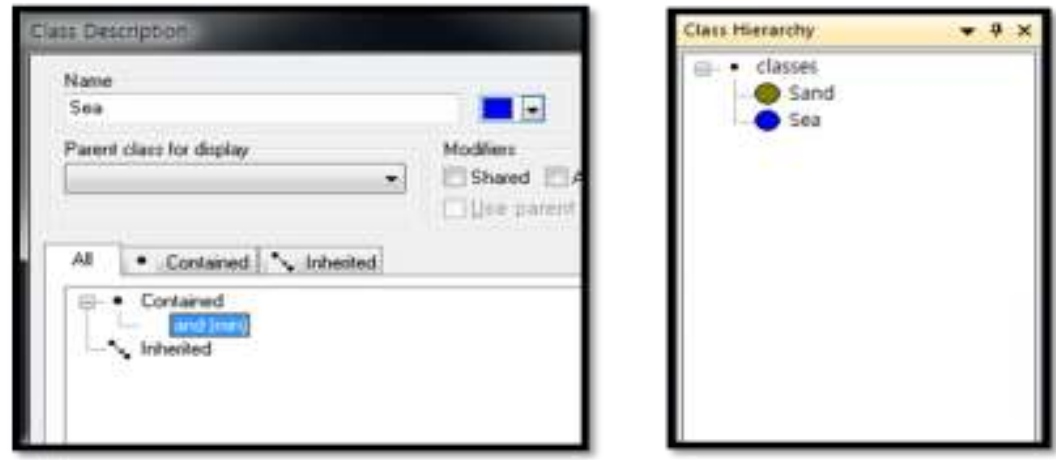

Figure 10. Feature Definition

The first classification result same as Figure 11 and Figure 12 shows merged result of water and sand classification.

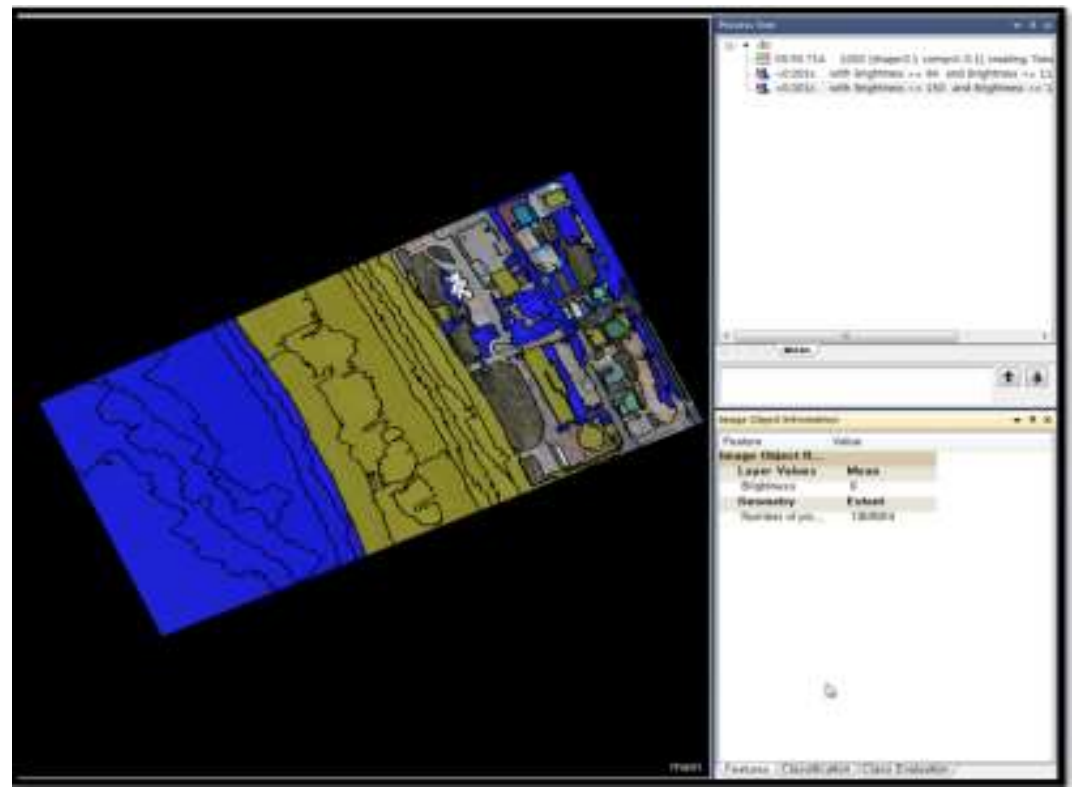

Figure 11. Classification Result 


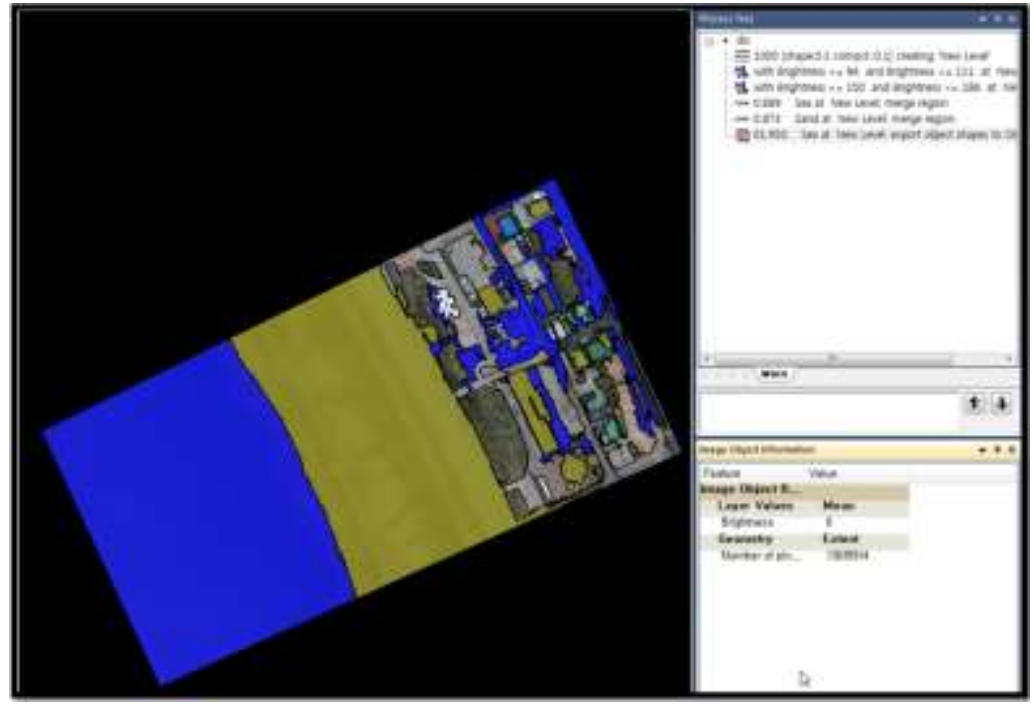

Figure 12. Merged Result

As shown in Figure 12, it can be seen that buildings in the city area are misclassified into the sea. The second classification was done by using DSM for detailed building classification. Rule set was created for building classification. The image classification process was performed in the order of building extraction using height values, and removal of trees. Figure 13 shows steps for building classification and Fig 14. Shows final result of extraction..

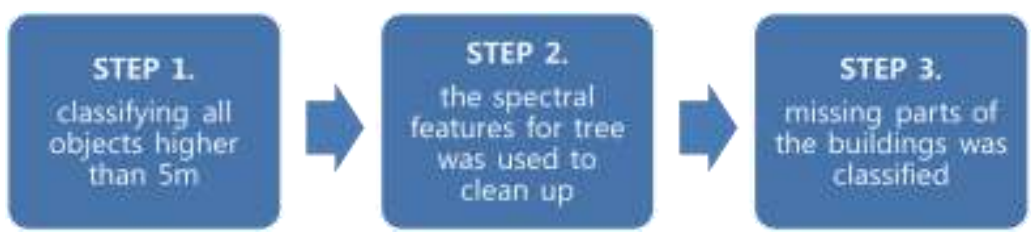

Figure 13. Steps for Building Extraction

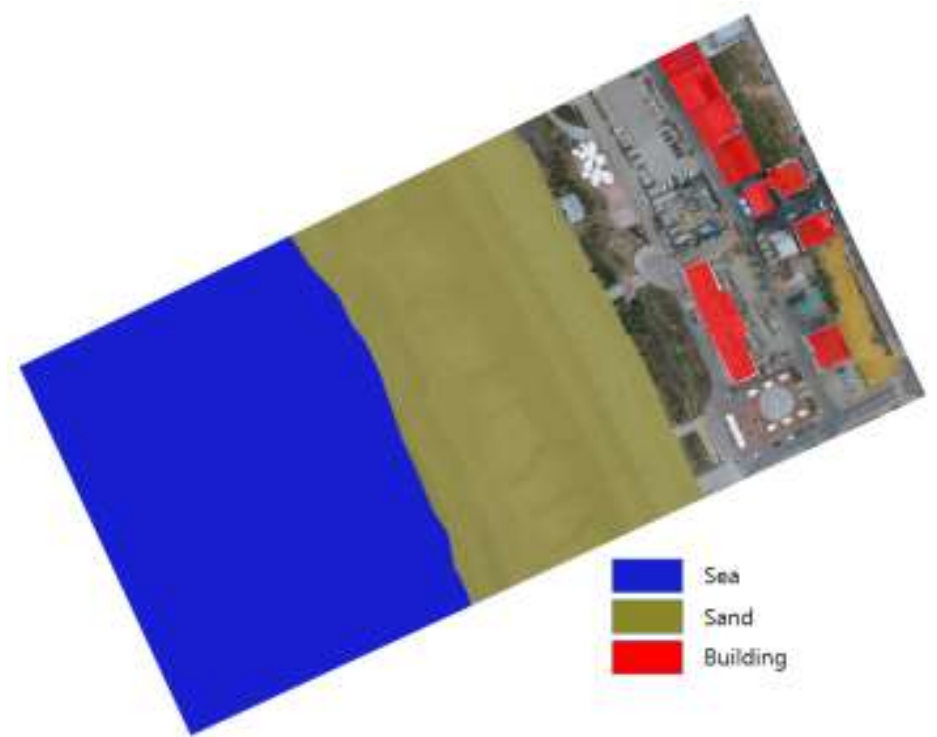

Figure 14. Final Result of Features Extraction 
In this study, extractions of features such as sea, sand and building was performed effectively using ortho image and DSM. Information about terrain, buildings and major facilities is very important for disaster prevention in urban areas. Especially, it is possible to create virtual flood data for coastal cities using altitude value of the DSM and these results can be used to plan for disaster prevention. The results of this study could use the basic data for disaster prevention.

\section{Conclusions}

In this study, UAV was used for construction of ortho image and DSM about study area and UAV ortho image and DSM were classified for construction of disaster prevention information. Following are the conclusions obtained in this study.

1. It was possible to effectively generate the ortho image and DSM in the study area using UAV image and post processing software.

2. If there are time-series data for a particular area, it can analyze topographic changes such as sedimentation, erosion and landslide because ortho image and DSM contain a lot of information about terrain and features.

3. Extraction the topographic features using the UAV data were performed effectively and the results of this study could use the basic data for disaster prevention.

\section{Acknowledgments}

This research was supported by Basic Science Research Program through the National Research Foundation of Korea(NRF) funded by the Ministry of Education, Science and Technology(No. NRF-2015R1A1A1A05001366).

\section{References}

[1] T. S. Lee and W. C. Cho, "A study on the Strategic Approach Method of the urban wastes for the Urban's Disaster Prevention and Safety Management", Journal of the Korean Society of Disaster \& Security, vol. 7, no. 1, (2014), pp. 27-33.

[2] H. S. Hwang, E. H. Choi and C. S. Kim, "A Disaster Victim Management System Using Geographic Information System", Journal of the Korean Association of Geographic Information Studies, vol. 14, no. 1, (2011), pp. 59-72.

[3] J. W. Lee, M. H. Seo and C. Han, "A Method of Site Selection for the Artificial Recharge of Groundwater Using Geospatial Data", Journal of the Korean Society of Surveying, Geodesy, Photogrammetry and Cartography, vol. 33, no. 5, (2015), pp. 427-436.

[4] J. H. Lee, "An Assessment Method for Hazardous Region of Flash Flood in Mountainous Areas", Journal of the Korea Academia-Industrial cooperation Society, vol. 11, no. 11, (2010), pp.4629-4634.

[5] S. Erdenesumbee, M. S. Cho and G. S. Cho, "Temporal Analysis on the Transition of Land Cover Change and Growth of Mining Area Using Landsat TM/+ETM Satellite Imagery in Tuv, Mongolia”, Journal of the Korean Society of Surveying, Geodesy, Photogrammetry and Cartography, vol. 32, no. 5, (2014), pp.451-457.

[6] S. K. Lee, S. K. Choi, S. T. Noh, N. Y. Lim and J. W. Choi, "Automatic Extraction of Initial Training Data Using National Land Cover Map and Unsupervised Classification and Updating Land Cover Map", Journal of the Korean Society of Surveying, Geodesy, Photogrammetry and Cartography, vol. 33, no. 4, (2015), pp.267-275.

[7] M. G. Kim and J. K. Park, "Assessment of Unmanned Aerial Vehicle for Management of Disaster Information", Journal of the Korea Academia-Industrial cooperation Society, vol. 16, no. 1, (2015), pp.697-702.

[8] S. T. Hong, J. W. Chang, “A New k-NN Query Processing Algorithm based on Multicastingbased Cell Expansion in Location-based Services, Journal of Convergence, vol. 4, no.4, (2013), pp.1-6.

[9] J. K. Park and K. W. Lee, "Classification of Buildings Using High Resolution UAV Image", Proceedings of the 3rd International Mega Conference on Green and Smart Technology, Jeju Island, Korea, (2016), December 21-23. 
[10] www.trimble.com

[11] S. Y. Park and J. S. Kim, "A Comparative Analysis of Landslide Susceptibility Assessment by Using Global and Spatial Regression Methods in Inje Area, Korea", Journal of the Korean Society of Surveying, Geodesy, Photogrammetry and Cartography, vol. 33, no. 6, (2015), pp. 579-587.

[12] J. K. Park and K. W. Lee, "Analysis of Geospatial Information about Submergence Area using UAV”, Science and Engineering Research Support Society, vol. 10, no. 12, (2016), pp. 31-40.

\section{Authors}

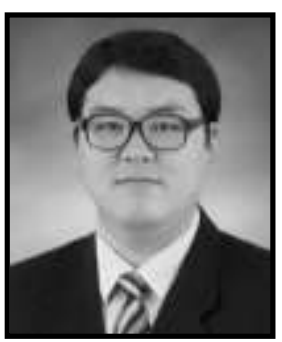

Joon-Kyu Park is Professor at the Department of Civil Engineering at Seoul University. He received his B.S., M.S. and Ph.D. degrees in Civil Engineering from Chungnam National University in 2001, 2003, 2008, respectively. His research interests are in the areas of GPS and Geo-Spatial Information Engineering.

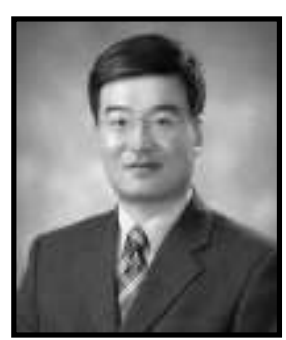

Keun-Wang Lee is Professor at the Department of Multimedia Science at Chungwoon University. He received his B.S. degree in Hanbat University in 1993. M.S. and Ph.D. degrees in Computer Science and Engineering from Soongsil University in 1996, 2000, respectively. His research interests are in the areas of Computer Science Engineering. 